\title{
Comparative Extraction of Chlorophylls in Selected Forest and Savanna Mosses Using Dimethylsulphoxide and Acetone
}

\author{
Fisayo S. AROYEHUN, Amos M. MAKINDE, Musibau O. ISA*
}

\author{
Obafemi Awolowo University, Faculty of Sciences,Department of Botany, Ile-Ife, Osun State, Nigeria; feasea4real@gmail.com; amakinde@oanife.edu.ng; \\ alamuola25@gmail.com (*orrespondingauthor)
}

\begin{abstract}
The present study compared the extraction of chlorophylls from selected forest mosses (Hyophila involuta and Thuidium gratum) and derived savanna moss (Archidium obioense) using dimethylsulphoxide (DMSO) and 80\% acetone. The mosses were collected from natural populations found in the Central Campus of the Obafemi Awolowo University, Ile-Ife, Nigeria. The chlorophyll extractions process followed standard methods and the absorbance of the extracts were read on spectrophotometer at wavelengths of $645 \mathrm{~nm}$ and 663 $\mathrm{nm}$ respectively. The data obtained were later subjected to appropriate statistical analysis. The results showed that DMSO was a better chlorophyll extractant for mosses than $80 \%$ acetone. Although there were significant differences in the chlorophyll $a$, chlorophyll $a / b$ ratio and total chlorophyll accumulation within all three species using DMSO and $80 \%$ acetone as extractant $(\mathrm{P}<0.05)$, there was no significant difference in the chlorophyll $b$ accumulation of all the three species $(\mathrm{P}>0.05)$.
\end{abstract}

Keywords: acetone, chlorophyll, dimethylsulphoxide, extractant, forest, savanna

\section{Introduction}

Bryophytes are the second largest group of land plants after flowering plants, comprising about 15,000 to 25,000 species worldwide (Gradstein et al., 2001). Members of this group have ancestral ties to the Chlorophyta (green algae), possessing chlorophyll $a$ and $b$ (Shaw, 2000). Chlorophyll, a natural pigment produced by green plants and algae, absorbs light energy from the sun, which is then used to synthesize carbohydrates from carbondioxide in a process called photosynthesis (Raven et al., 2005). Chlorophyll content can change in response to biotic and abiotic stresses such as pathogen infection (Mur et al., 2010) and light stress (Kitajima and Hogan, 2003; Brouwer et al., 2012).

Chlorophyll analysis has been conducted in numerous studies due to its importance in the physiology of plants. Thus, quantification of chlorophyll provides important information about the effects of environments on plant growth (Schlemmer et al., 2005). In addition to this, the extraction techniques of chlorophyll deserve special attention. It is necessary to have an accurate and efficient method to extract and measure chlorophyll from mosses. Even more, the location of chlorophyll in leafs makes the penetration of solvent and dissolution of chlorophyll a very complex process that is hard to predict and control (ShuMei et al., 2014). Currently, there are several methods for chlorophyll estimation. Some of the methods involve many procedural steps, which lead to dilution or loss of pigments. Extraction of chlorophyll in acetone has been the common method among bryologist (Wolf, 1958; Martin and Churchill, 1982; Glime and Keen, 1984; Penuelas, 1984).
Raeymaekers and Longwith (1987) and Makinde and Akande (2012) used dimethylsulfoxide (DMSO) to extract chlorophyll from mosses and the method circumvented the difficulties arising due to the maceration using acetone. Most of the traditional methods of pigment analysis, including the often used High Performance Liquid Chromatography (HPLC) are not ideal to obtain long term data (Sims and Gamon, 2002).

The present work therefore intended to compare the extraction of chlorophyll contents from selected forest mosses (Hyophila involuta and Thuidium gratum) and derived savanna moss (Archidium obioense) using dimethylsulfoxide (DMSO) and 80\% acetone. The results from this work may also provide information about the changes that can be observed within mosses of the two vegetation zones.

\section{Materials and Methods}

\section{Plant materials}

The plant materials consisted in different moss species: Archidium obioense Schimp ex. C. Muell, Hyophila involuta (Hook) Jaeg. and Thuidium gratum (Palis) Jaeg.; samples were collected from their natural populations, for a period of nine months, at the Obafemi Awolowo University (O.A.U) Ile-Ife campus, in Southwest of Nigeria $\left(07^{\circ} 32 \mathrm{~N}\right.$; $\left.04^{\circ} 31^{\prime} \mathrm{E}\right)$.

\section{Chlorophyll extraction}

The chlorophyll contents of the mosses shoots were extracted using $80 \%$ acetone according to the method of Raeymaekers and Longwith (1987) and absolute 
348

dimethylsulfoxide (DMSO) according to the method of Makinde and Akande (2012).

The extraction was done using $10 \mathrm{mg}$ of each moss sample, placed in a test tube and $5 \mathrm{ml}$ of DMSO added. Each test tube was covered with aluminum foil and thereafter incubated at $67^{\circ} \mathrm{C}$ in the oven (Genlab Drying cabinet) for 15 hours. For acetone extraction, $10 \mathrm{mg}$ of each moss sample were grounded in $80 \%$ acetone, with mortar and pestle after which about $0.8 \mathrm{~g}$ of sodium bicarbonate had been added. Following complete maceration, samples were filtered into test tubes using Whatman No.1 filter paper.

\section{Spectrophotometric assays}

The absorbance of the extracts was read on VIS S23A Spectrophotometer at wavelengths of $645 \mathrm{~nm}$ and $663 \mathrm{~nm}$. The concentrations of chlorophyll $a$ and $b(\mathrm{mg} / \mathrm{g})$ dry weight (DW) were determined using the formulae of Arnon (1949), respectively the total chlorophyll was calculated using the formula of Vernon (1960):

Chlorophyll $a=\left(12.7_{\mathrm{A} 663}-2.7_{\mathrm{A} 645}\right) \times \mathrm{SW}^{-1}$

Chlorophyll $b=\left(22.9_{\mathrm{A} 645}-4.7_{\mathrm{A} 663}\right) \times \mathrm{SW}^{-1}$

Total chlorophyll $=\left(6.45_{\mathrm{A} 663}+17.72_{\mathrm{A} 645}\right) \times \mathrm{SW}^{-1}$

Where: $\mathrm{S}=$ amount of solvent used for extraction $(\mathrm{ml})$, $\mathrm{W}=$ weight of moss sample $(\mathrm{mg})$.

\section{Statistical analysis}

Data obtained were analyzed using t-test to determine if there were significant differences between the two extratants studied at $\mathrm{P}=0.05$, while one-way analysis of variance (ANOVA) was used to determine whether there were significant differences between the three moss species.

\section{Results}

\section{Chlorophyll extraction}

The concentrations of chlorophyll $a$ and $b$ of Archidium obioense, Hyophila involuta and Thuidium gratum from absolute DMSO and $80 \%$ acetone extracts are shown in Figs. 1, 2 and 3 respectively, while the concentrations of total chlorophyll and that of chlorophyll $a / b$ ratios for the species under study are shown in Figs. 4, 5 and 6 respectively.

Chlorophyll $a, b, a / b$ ratios and total chlorophyll concentrations in both DMSO and $80 \%$ acetone extracts showed similar patterns, by recording lower values of chlorophyll concentrations between April and July for all the species studied. High values were later recorded, reaching the peak in October and thereafter declined in November, except that in Thuidium gratum chlorophyll $a / b$ ratio that reached the peak in August and declined in September (Fig. 3). Also in Hyophila involuta, chlorophyll $a$, total chlorophyll and chlorophyll $a / b$ ratio recorded peak values in September, and thereafter declined in October (Fig. 2).

Comparing the data for the three mosses species (Figs. 7 to 10) it was observed that Thuidium gratum had the highest chlorophyll $a, b$, total chlorophyll $(6.89,1.25,8.32)$ $\mathrm{mg} / \mathrm{g}$ dry weight (DW) and $a / b$ ratio $(6.56)$ respectively; it was followed by Hyophila involuta $(5.01,1.06,7.60) \mathrm{mg} / \mathrm{g}$ DW, 4.71) while the least content was recorded by

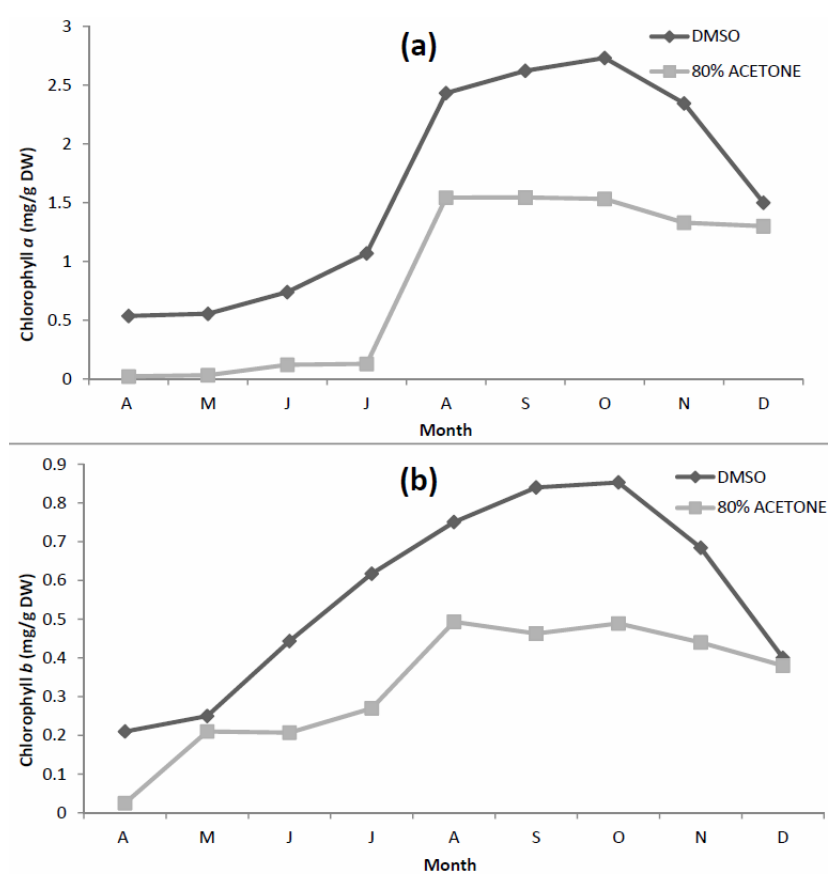

Fig. 1. (a) Time-course of changes in chlorophyll a concentration in Archidium obioense; (b) Time-course of changes in chlorophyll $b$ concentration in A. obioense; AApril, M- May, ..., D- December
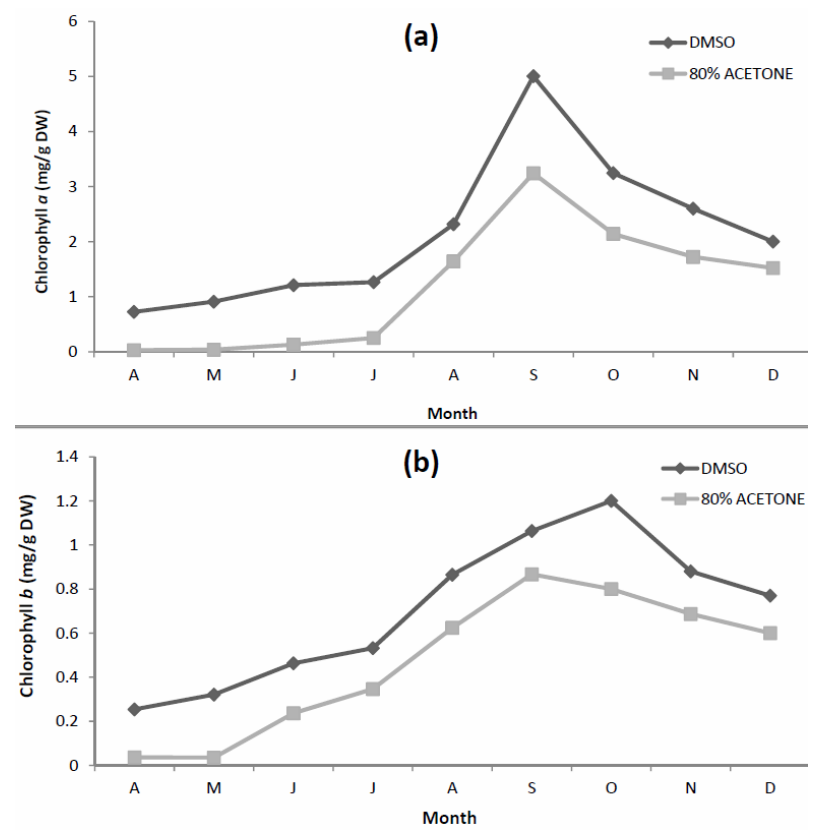

Fig. 2. (a) Time-course of changes in chlorophyll a concentration in Hyophila involuta; (b) Time-course of changes in chlorophyll $b$ concentration in $H$. involuta; AApril, M- May, ..., D- December

Archidium obioense (2.72, 0.85, 3.49) mg/g DW, 3.53). Low chlorophyll accumulation was recorded for all species between April and July, period that corresponded with the beginning of rainfall. High level of chlorophyll accumulation was recorded in the rest of the months and begun to decline between October until December, a period dominated by drought. 

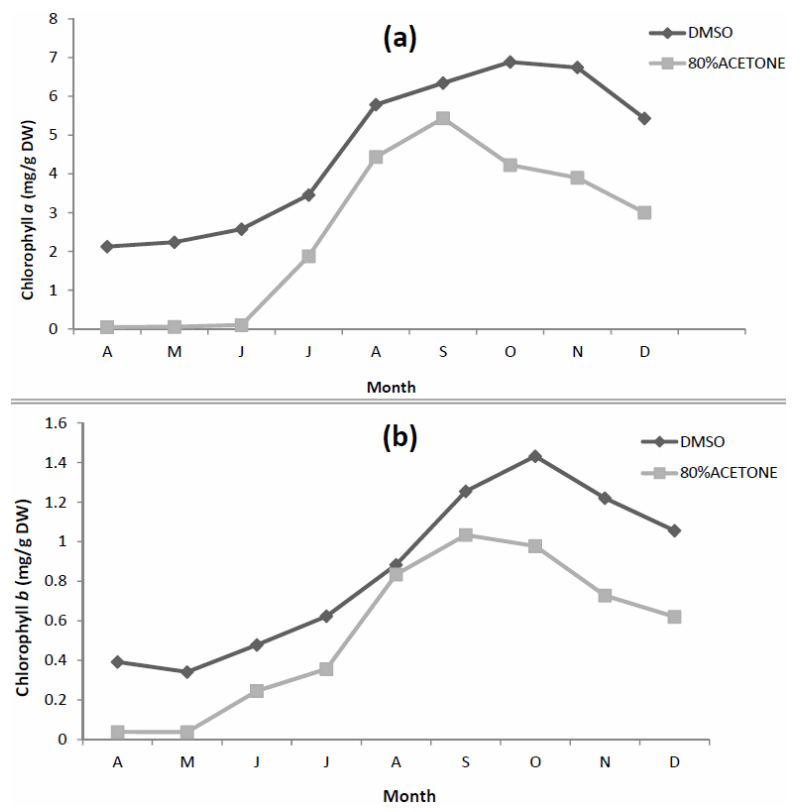

Fig. 3. (a) Time-course of changes in chlorophyll a concentration in Thuidium gratum; (b) Time-course of changes in chlorophyll $b$ concentration in T. gratum; A- April, M- May, ..., D- December

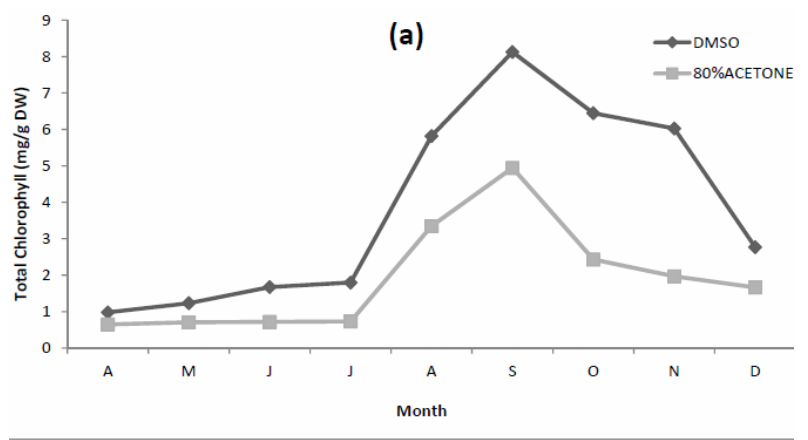

(b)

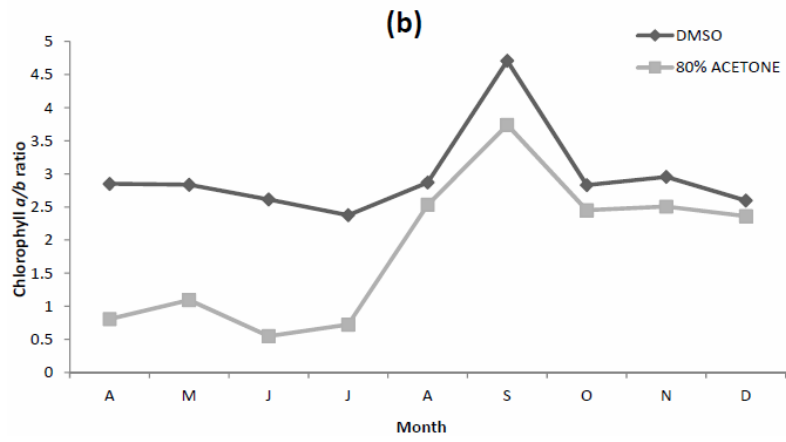

Fig. 5. (a) Time-course of total chlorophyll accumulation in Hyophila involuta; (b) Time-course of changes in chlorophyll $a / b$ ratio in H. involuta; A- April, M- May, ..., D- December

Generally, DMSO chlorophyll extracts from savanna moss (Archidium obioense) and the two forest mosses (Thuidium gratum and Hyophila involuta) recorded the highest chlorophyll $a$, chlorophyll $b$, chlorophyll $a / b$ ratio and total chlorophyll content throughout the study period.
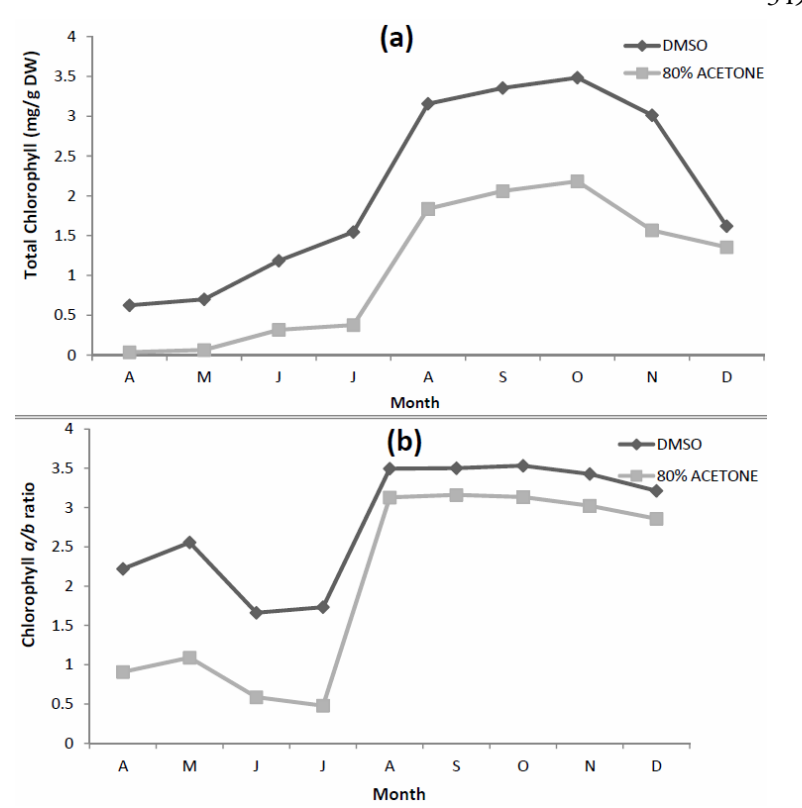

Fig. 4. (a) Time-course of total chlorophyll accumulation in Archidium obioense; (b) Time-course of changes in chlorophyll $a / b$ ratio in A. ohioense; A- April, M- May, ..., D- December
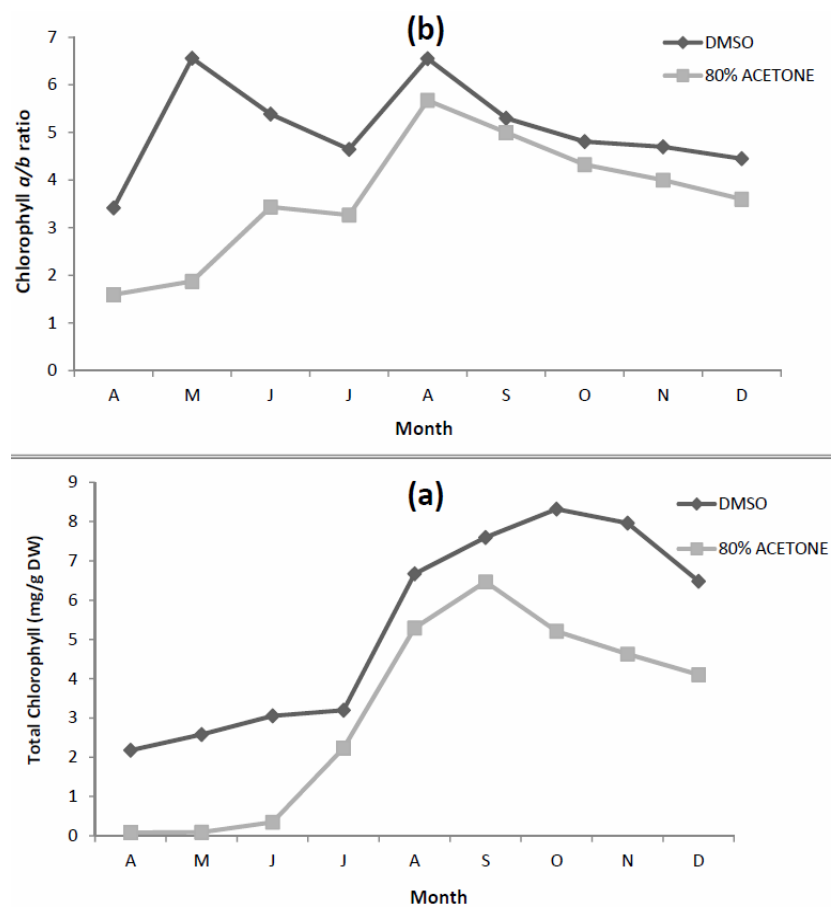

Fig. 6. (a) Time-course of total chlorophyll accumulation in Thuidium gratum; (b) Time-course of changes in chlorophyll $a / b$ ratio in T. gratum; A- April, M- May, ..., D- December

\section{Statistical analysis}

The results of the t-test showed that chlorophyll $a$ and total chlorophyll accumulation observed within the two extractants were not significantly different $(\mathrm{P}>$ $0.05)$, while the chlorophyll $b$ and chlorophyll $a / b$ ratio noted were significantly different. 

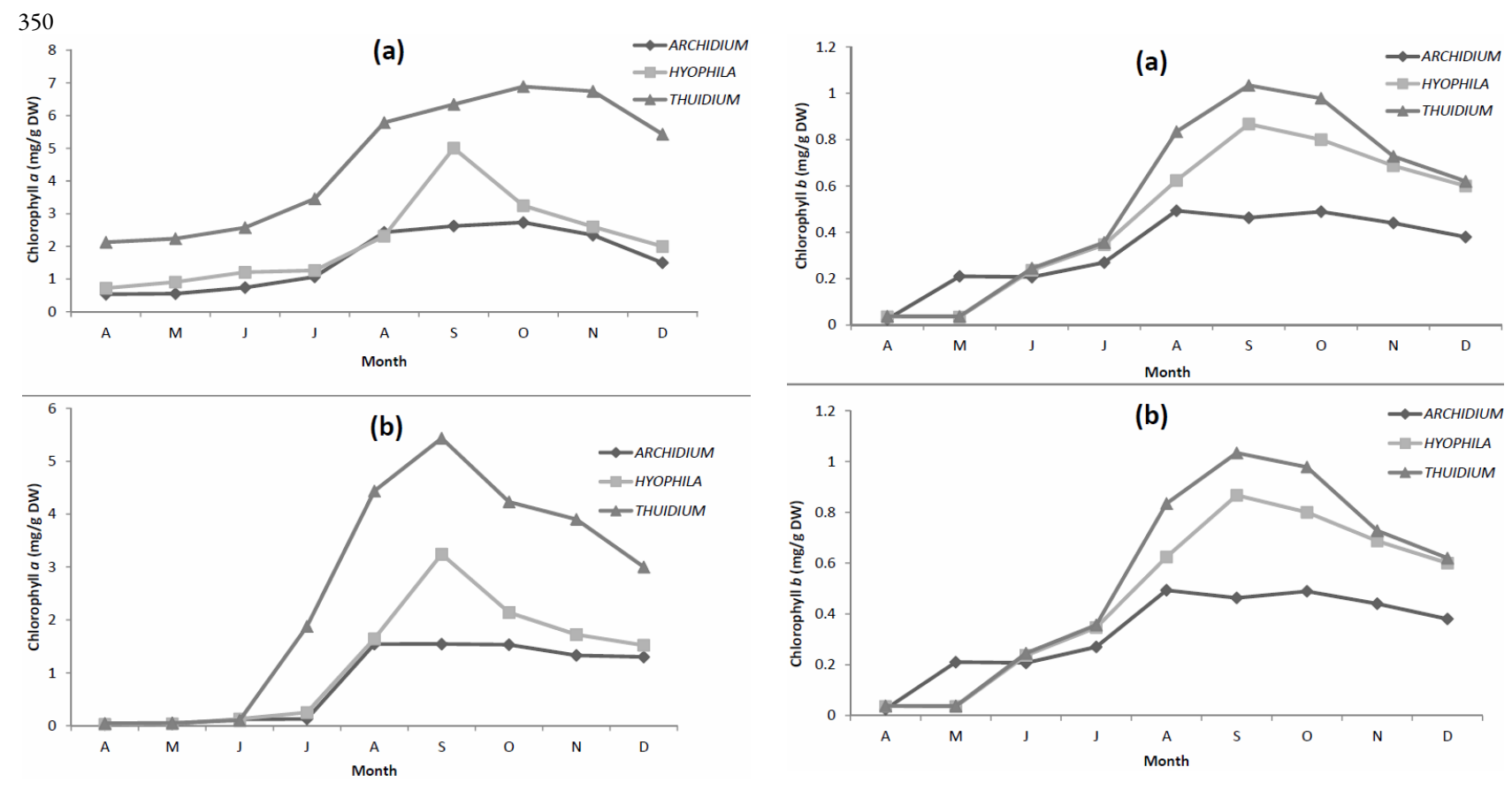

Fig. 7. (a) Time-course of changes in chlorophyll a concentration in dimethylsulphoxide extract for selected mosses species; (b) Time-course of changes in chlorophyll a concentration in $80 \%$ acetone extract for selected mosses species; A- April, M- May, ..., D- December
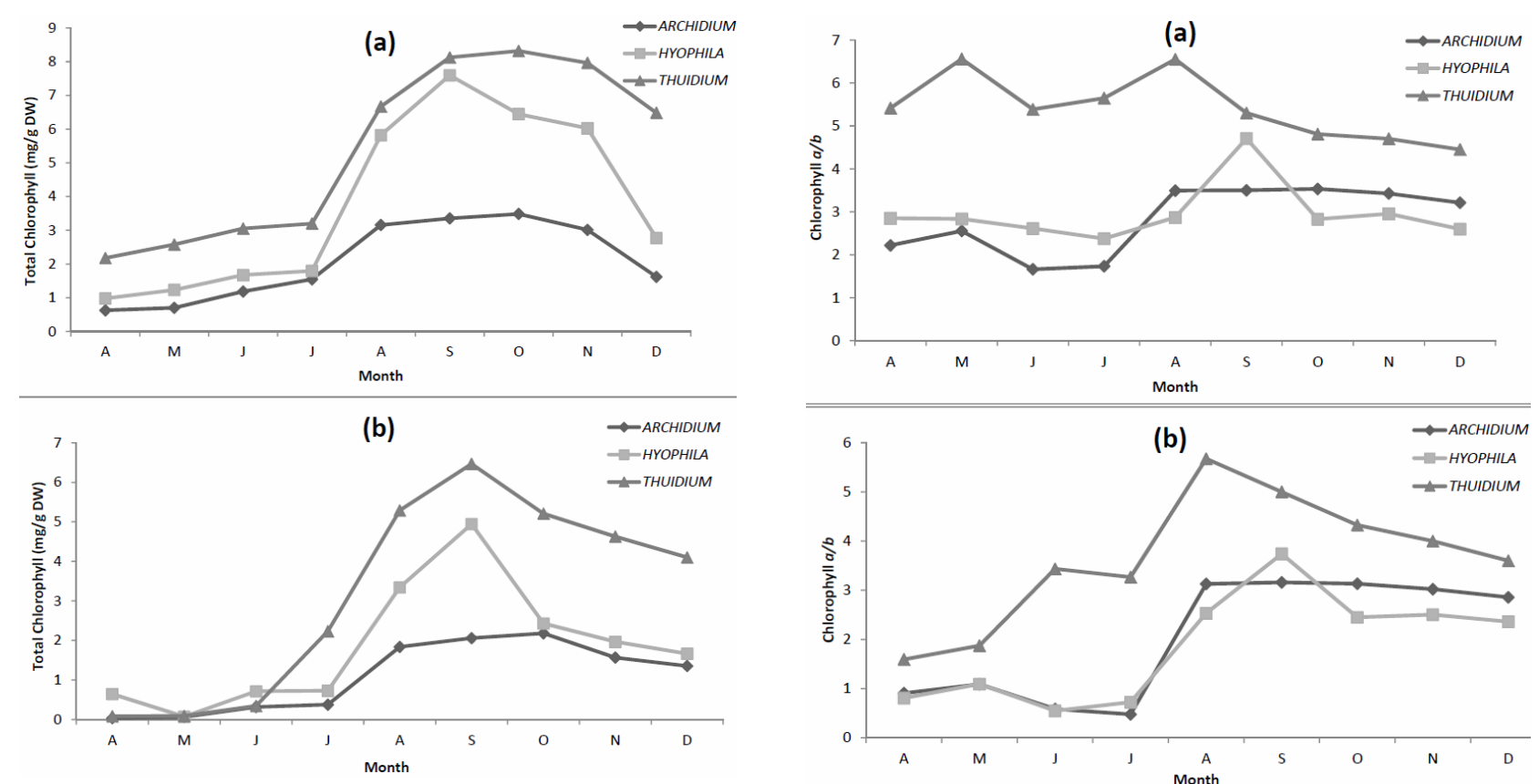

Fig. 8. (a) Time-course of changes in chlorophyll $b$ concentration in dimethylsulphoxide extract for selected mosses species; (b) Time-course of changes in chlorophyll $b$ concentration in $80 \%$ acetone extract for selected mosses species; A- April, M- May, ..., D- December

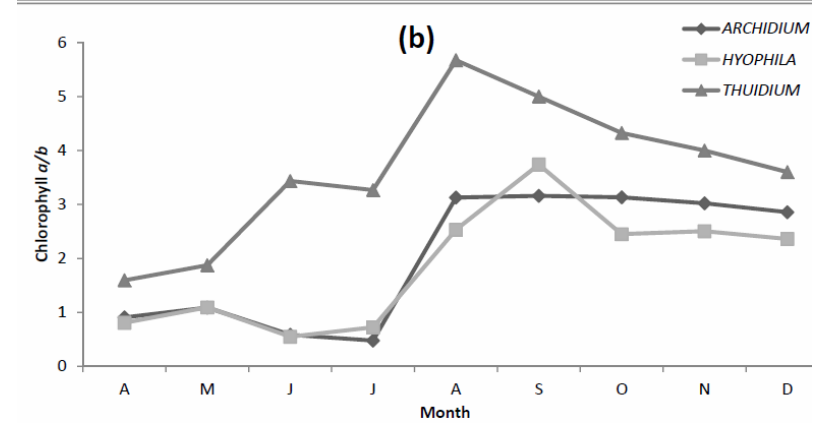

Fig. 9. (a) Time-course of total chlorophyll accumulation in dimethylsulphoxide extract for selected mosses species; (b) Time-course of total chlorophyll accumulation in $80 \%$ acetone extract for selected mosses species; A- April, M- May, ..., DDecember

Fig. 10. (a) Time-course of changes in chlorophyll $a / b$ ratio in dimethylsulphoxide extract for selected mosses species; (b) Time-course of changes in chlorophyll $a / b$ ratio in $80 \%$ acetone extract for selected mosses species; A- April, M- May, ..., D- December 
The result of the ANOVA showed that there were significant differences in the chlorophyll $a$, chlorophyll $a / b$ ratio and total chlorophyll accumulation among all three species using DMSO and $80 \%$ acetone as extractant $(\mathrm{P}<0.05)$ respectively. However, there was no significant difference in the chlorophyll $b$ accumulation of all the three species $(\mathrm{P}>0.05)$.

\section{Discussion}

The patterns of chlorophyll accumulation reported in this work clearly showed that DMSO is a reliable and reproducible extractant to extract chlorophyll in mosses. The method of extracting chlorophyll using DMSO does not require maceration of the plant samples, thus might increase the efficiency of the study. The elimination of this step reduced analytical errors and yielded a solvent with less turbidity, such as found in $80 \%$ acetone extract. DMSO gave a more complete extraction of chlorophyll pigments, which were also more stable over time than those with $80 \%$ acetone. This interpretation of the results agreed with those of Alberte et al. (1976), Raeymaekers and Longwith (1987). Bryophytes have relatively thick cells, relative to the size of protoplast, so the extraction of chlorophyll from them required a lot of time (Makinde and Akande, 2012). The submersion of these mosses in DMSO for 12 hours at $67^{\circ} \mathrm{C}$ was found to be appropriate and efficient in this regard.

Water deficiency is known to cause reduced photosynthesis (Dilks and Proctor, 1974). Thus, a more intense chlorophyll accumulation was recorded within the current study during the rainy season and less chlorophyll occurred during the dry season. Di-Nola et al. (1983) also reported that chlorophyll contents of fresh sample of Mniobryum sp., Barbula fallax and Tortula brevissima were much higher than those in the dry states.

The accumulation of chlorophyll in Thuidium gratum and Hyophila involuta (forest moss species) was higher than that of the derived savanna mosses, Archidium obioense. This could be due to the fact that these forest mosses possess leaves in which chlorocysts are sandwitched between several layers of large empty non-chlorophyllous hyalocysts, as a result of which the photosynthetic cells are protected from photo-oxidation (Fisher, 2006).

Boardman (1977) also reported higher chlorophyll concentrations in leaves of plants growing in environment characterized by low irradiances (e.g. in deep shade) relative to those in higher irradiances (e.g. open environment). Such changes in the characteristics of the chlorophyll content appear to represent adaptations to enhance the efficiency of light capture. Sluka (1983) also supported the concept of increased chlorophyll concentrations at low light intensities in bryophytes by showing that total chlorophyll content of mosses was inversely proportional with the light intensity. It has been widely accepted that photosynthetic pigments, mostly chlorophyll $a$ and $b$ tends to increase with decreasing irradiance in order to facilitate increased light harvesting in shade tolerant species (Givnish, 1988). In the present study, it was observed that the chlorophyll content increased in mosses under low light. High chlorophyll contents under low light situations found in Thuidium gratum and Hyopila involuta can therefore be related to their occurrence or distribution.
In terrestrial plants that grow within the shade of a leaf canopy, chlorophyll $b$ concentrations increase more than those of chlorophyll $a$ because chlorophyll $b$ utilizes a slightly narrower wavelength span in accordance with the spectrum found there (Martin and Churchill, 1982; Marschall and Proctor, 2004). This also agreed with what was reported for seagrass (Sharon et al., 2011). The occurrence of lower chlorophyll $a / b$ ratios in shade plants compared with sun plants was obtained as a consequence of chlorophyll $b$ associated only with light harvesting chlorophyll protein (LHCP) complex of the photosynthetic unit, whereas chlorophyll $a$ is found in LHCP and in other complexes and does not change in response to environmental conditions (Alberte et al., 1976). The low chlorophyll $a / b$ ratio might also be as a result of large amount of light-harvesting chlorophyll protein (LHCP) complexes in the thylakoids of mosses (Aro, 1982b). LHCP complex have chlorophyll $a$ and $b$ in about equal amounts, whereas the photosystems (PS1 and PS11) have much more chlorophyll $a$ than chlorophyll $b$ (Salisbury and Ross, 1985). This explained the lower chlorophyll $a / b$ ratio recorded by forest moss Hyophila involuta than the sun demanding species Archidium obioense, in August, October, November and December.

Apart from the total chlorophylls, the ratio of chlorophyll $a$ to $b$ has been a key parameter to judge the shade tolerance of a particular species (Givnish, 1988); thus, shade tolerant species display a lower ratio under shade compared to their counterparts grown under high light environments. It has been shown that shade tolerant species produce a higher proportion of chlorophyll $b$ relative to chlorophyll a, which leads to a lower chlorophyll $a / b$ ratio, to enhance the efficiency of blue light absorption in low light environments (Yamazaki et al., 2005). Forest mosses in the present study responded in the opposite direction. Higher chlorophyll $a / b$ ratio values were obtained under lower light intensities. This finding challenges the validity of using low chlorophyll $a / b$ ratio as an indicator of shade tolerance of species in general.

Several studies reported decreased chlorophyll $a / b$ ratio in response to shade (Kotzabasis et al., 1999), while a few studies reported an unchanged chlorophyll $a / b$ ratios in the light gradient continuum (Murchie and Horton, 1998). Johnson et al. (1993) and Murchie and Horton (1998) showed only a weak association between chlorophyll $a / b$ ratio and shade tolerance. Therefore, it is proposed that the changes in chlorophyll $a / b$ ratio depending on the light environment might be a characteristic of species themselves. Increase in PS I units (size or number) explained the increased chlorophyll $a / b$ ratio under low light, as PS I often does not contain chlorophyll $b$ (Hirashima et al., 2006). On the other hand, increased number of PS II reaction centre also supports higher chlorophyll $a / b$ ratio under low light.

The concept of sun and shade plants, which was developed with and for the leaves of vascular plants (Givnish, 1988; Larcher, 2003) does not seem to be fully coherent for mosses; they show corresponding patterns to some extent, but there is substantially more variation (Lovelock and Robinson, 2002; Marschall and Proctor, 2004). Water availability can be an important source of this 
352

variability in mosses as exemplified by Ueno (2006).

\section{Conclusions}

Dimethylsulfoxide (DMSO) was a reliable and reproducible extractant to extract chlorophyll from mosses. The most chlorophyll accumulation was recorded during the rainy season. The accumulation of chlorophyll in Thuidium gratum and Hyophila involuta (forest moss species) was higher than that of the derived savanna mosses, Archidium ohioense. Higher chlorophyll accumulation in the forest moss species than that of the derived savanna mosses also provide information about the changes that may be observed in mosses of the two vegetation zones, with a possible strong influence from the water availability. Higher chlorophyll $a / b$ ratio values were obtained in the current study under lower light intensities. These findings challenge the validity of using low chlorophyll $a / b$ ratio as an indicator of shade tolerance of species in general, and enhance the need of further study mosses.

\section{Acknowledgements}

This research received no specific grant from any funding agency in the public, commercial, or not-for-profit sectors.

\section{References}

Alberte RS, McClure PR, Thornber JP (1976). Photosynthesis in trees organization of chlorophyll and photosynthetic unit size in isolated gymnosperm chloroplast. Plant Physiology 58:341-344.

Arnon D (1949). Copper enzymes in isolated chloroplasts, polyphenoxidases in Beta vulgaris. Plant Physiology 24:1-15.

Aro EM (1982b). A comparison of the chlorophyll-protein composition and chloroplast ultrastructure in two bryophytes and two higher plants. Zeits Pflanzenphysiology 108:97-105.

Boardman NK (1977). Comparative photosynthesis of sun and shade plants. Annual Review of Plant Physiology 28:355-377.

Brouwer B, Ziolkowska A, Bagard M, Keech O, Gardeström P (2012). The impact of light intensity on shade-induced leaf senescence. Plant Cell Environment 35:1084-1098.

Di-Nola L, Mayer AM, Heyn CC (1983). Respiration, photosynthesis and drought tolerance in mosses from various habitats in Israel. Israel Journal of Botany 32:189-202.

Dilks TJK, Proctor MCF (1974). The pattern of recovery of bryophytes after desiccation. Journal of Bryology 8:97-115.

Fisher KM (2006). Rank-free monography: A practical example from the moss clade Leucophanella (Calymperaceae). Systematic Botany 31(1):13-30.

Givnish TJ (1988). Adaptation to sun and shade: a whole plant perspective. Australian Journal of Plant Physiology 15:63-92.

Glime JM, Keen RE (1984). The importance of bryophytes in a mancentered world. Journal of Hattori Botany Laboratory 55:133146.

Gradstein SR, Churchill SP, Salazar AN (2001). Guide to the bryophytes of tropical America. Memoirs of the New York Botanical Garden. New York: New York Botanical Garden Press.
Hirashima M, Satoh S, Tanaka R, Tanaka A (2006). Pigment shuffling in antenna systems achieved by expressing prokaryotic chlorophyllide $a$ oxigenase in Arabidopsis. Journal of Biological Chemistry 281:15385-15393.

Johnson GN, Scholes JD, Horton P, Young AJ (1993). Relationships between carotenoid composition and growth habit in British plant species. Plant Cell and Environment 16:681-686.

Kitajima K, Hogan KP (2003). Increases of chlorophyll $a / b$ ratios during acclimation of tropical woody seedlings to nitrogen limitation and high light. Plant Cell Environment 26:857-865.

Kotzabasis K, Strasse RB, Navakoudis E, Senger H, Dorneman N (1999). The regulatory role of polyamines in structure and functioning of the photosynthetic apparatus during photoadaptation. Journal of Photochemistry and Photobiology 50:45-52.

Larcher W (2003). Physiological plant ecology. Springer 4th ed.

Lovelock CE, Robinson SR (2002). Surface reflectance properties of Antarctic moss and their relationship to plant species, pigment composition and photosynthetic function. Plant Cell Environment 25:1239-1250.

Makinde AM, Akande FI (2012). Effect of lead and simulated acid rain on chlorophyll contents of selected tropical mosses. Ife Journal of Science 14:309-313.

Marschall M, Proctor MCF (2004). Are bryophytes shade plants? Photosynthetic light responses and proportions of chlorophyll $a$, chlorophyll $b$ and total carotenoids. Annals of Botany 94:593603.

Martin CE (1980). Chlorophyll $a / b$ ratios of eleven North Carolina mosses. Bryologist 83:84-87.

Martin CE, Churchill SP (1982). Chlorophyll concentrations and $a / b$ ratios in mosses collected from exposed and shaded habitats in Kansas. Journal of Bryology 12:297-304.

Mur LAJ, Aubry S, Mondhe M, Kingston-Smith A, Gallagher J, Timms-Taravella E, Ougham H (2010). Accumulation of chlorophyll catabolites photosensitizes the hypersensitive response elicited by Pseudomonas syringae in Arabidopsis. New Phytologist 188:161-174.

Murchie EH, Horton P (1998). Contrasting patterns of photosynthetic acclimation to the light environment are dependent on the differential expression of the responses to altered irradiance and spectral quality. Plant Cell and Environment 21:139-148.

Penuelas J (1984). Pigments of aquatic mosses of the river Muga, NE Spain, and their response to water pollution. Bryologist 10:127132.

Raeymaekers G, Longwith JE (1987). The use of dimethyl sulphoxide (DMSO) as a solvent to extract chlorophyll from mosses. Symposia Biologica Hungarica 35:151-164.

Raven PH, Evert RF, Eichhorn SE (2005). Biology of plants. WH Freeman and Company, New York.

Salisbury FB, Ross CW (1985). Plant physiology. Wadsworth Publishing Company Inc, Belmont, Calif pp 129-135.

Schlemmer MR, Francis DD, Shanahan JF, Schepers JS (2005). Remotely measuring chlorophyll content in corn leaves with 
differing nitrogen levels and relative water content. Agronomy Journal 97:106-112.

Sharon Y, Levitan O, Spungin D, Ilana B, Beer S (2011). Photoacclimation of the seagrass Halophila stipulacea to the dim irradiance at its 48-meter depth limit. Limnology and Oceanography 56(1):357-362.

Shaw J (2000). Phylogeny of the Sphagnopsida based on nuclear and chloroplast DNA sequences. Bryologist 103:277-306.

Shu-Mei H, Ban-Dar H, Sanboh L (2014). Modelling of isothermal chlorophyll extraction from herbaceous plants. Journal of Food Engineering 128:17-23.

Sims DA, Gamon JA (2002). Relation between pigment content and spectral reflectance across a wide range of species, leaf structures and development stages. Remote Sensing of Environment 81:337-354.

Sluka ZA (1983). The dependence of the chlorophyll content and the leaf-area of mosses on the ecological conditions. Vestnik Moskovskovskogo Universitet Series XVI Biology 37(3):24-29.
Ueno T (2006). Photosynthetic light responses of a widespread moss, Sanionia uncinata, from contrasting water regimes in the high Arctic tundra, Svalbard, Norway. Journal of Bryology 28:345-349.

Vernon LP (1960). Spectrophotometric determination of chlorophyll and phaeophytin in plant extract. Analytical Chemistry 3:11441150.

Wolf FT (1958). Comparative chlorophyll content of the two generations of bryophytes. Nature 181:579-580.

Yamazaki J, Takahisa S, Emiko M, Yasumaro K (2005). The stoichiometry and antenna size of the two photosystems in marine green algae, Bryopsis maxima and Ulva pertusa, in relation to the light environment of their natural habitat. Journal of Experimental Botany 56(416):1517-1523. 